\title{
A Survey of Copy Number Variants Associated with Neurodevelopmental Disorders in a Large-Scale, Multi-Ancestry Biobank
}

\section{Authors:}

Rebecca Birnbaum, MD ${ }^{1,2}$, Behrang Mahjani ${ }^{1,3}$, PhD, Ruth J.F. Loos, PhD ${ }^{4,5}$, Andrew J. Sharp, PhD 2,6

\author{
Affiliations: \\ ${ }^{1}$ Department of Psychiatry, Icahn School of Medicine at Mount Sinai, \\ ${ }^{2}$ Department of Genetics and Genomic Sciences, Icahn School of Medicine at Mount Sinai \\ ${ }^{3}$ Seaver Autism Center for Research and Treatment, Icahn School of Medicine at Mount Sinai \\ ${ }^{4}$ Charles Bronfman Institute for Personalized Medicine, Icahn School of Medicine at Mount Sinai \\ ${ }^{5}$ Novo Nordisk Foundation Center for Basic Metabolic Research, University of Copenhagen, Denmark \\ ${ }^{6}$ The Mindich Child Health and Development Institute, Icahn School of Medicine at Mount Sinai
}

Correspondence: Rebecca Birnbaum, MD, rebecca.birnbaum@mssm.edu

Keywords: Copy Number Variant, Biobank, Neurodevelopmental Disorders, Autism Spectrum Disorders, Schizophrenia

\section{ACKNOWLEDGEMENTS:}

We thank individuals within the BioMe Biobank for their participation. We thank Regeneron Genetics Center for contribution to the exome sequencing and the CLAMMS CNV call set; and the IT group at the Icahn School of Medicine at Mount Sinai for computing and database support.

\section{CONFLICT OF INTEREST:}

The authors declare no conflicts of interest.

\section{FUNDING:}

RB is supported by NIMH K23 MH112955-02 (PI: Birnbaum). 
medRxiv preprint doi: https://doi.org/10.1101/2021.06.09.21258554; this version posted June 12, 2021. The copyright holder for this preprint (which was not certified by peer review) is the author/funder, who has granted medRxiv a license to display the preprint in perpetuity.

It is made available under a CC-BY 4.0 International license.

\section{ABSTRACT}

BACKGROUND: Past clinical genetic studies have identified rare, copy number variants (CNVs) as risk factors for multiple neurodevelopmental disorders (NDD), including autism spectrum disorder and schizophrenia. However, the broad, clinical characterization of these NDD-CNVs in large population cohorts, especially of diverse ancestry, is relatively understudied. We characterized the clinical presentation of NDD-CNVs in the BioMe biobank, comprising $\sim 25,000$ individuals across diverse ancestry, medical and neuropsychiatric clinical presentation, with a mean age of 50.3 years.

METHODS: Individuals within the BioMe biobank harboring NDD-CNVs were identified using a consensus of two CNV calling algorithms, based on whole-exome sequencing and genotype array data, followed by a series of novel, in-silico clinical assessments.

RESULTS: The overall prevalence of a set of 64 NDD-CNVs was calculated at $\sim 2.5 \%$, with prevalence varying by locus, corroborating the presence of some relatively, highly-prevalent NDDCNVs (i.e., 15q11.2 deletion/duplication, 2q13(NPHP1) deletion/duplication). An aggregate set of rare, NDD-CNVs were enriched for congenital disorders $(O R=1.8, p$-value $=0.02)$ and major depressive disorders $(\mathrm{OR}=1.3, \mathrm{p}$-value $=0.04)$ in multi-ancestry analyses, and major depressivedisorder in an African ancestry-stratified group (OR=1.8, $p$-value=0.01). In a meta-analysis of medical diagnoses ( $n=195$ hierarchically-clustered diagnostic codes), an aggregated set of rare, NDD-CNVs was significantly associated with obstructive sleep apnea (Z-score=3.6 $p=3.2 \times 10^{-4}$ ). Further, an aggregated set of rare, NDD-CNVs was associated with increased body mass index (BMI) in a multi-ancestry analysis (Beta=0.14, p-value=0,04), and in Hispanic-stratified analyses

$\left(\right.$ Beta $=0.30, p$-value $\left.=4.2 \times 10^{-3}\right)$. For 38 common serum laboratory tests, there was no identified association with an aggregate set of NDD-CNVs. 
medRxiv preprint doi: https://doi.org/10.1101/2021.06.09.21258554; this version posted June 12, 2021. The copyright holder for this preprint (which was not certified by peer review) is the author/funder, who has granted medRxiv a license to display the preprint in perpetuity.

It is made available under a CC-BY 4.0 International license .

CONCLUSION: The current analyses elucidated clinical features of individuals harboring NDDCNVs, in a large-scale, multi-ancestry biobank, identifying enrichments for congenital disorders and major depressive disorder, as well as identifying associations with obesity-related phenotypes, obstructive sleep apnea and increased BMI. Future recall of individuals harboring NDD-CNVs will allow for further clinical assessments beyond the electronic health records (EHR) presently analyzed, including neurocognitive and neuroimaging outcomes.

\section{INTRODUCTION}

Clinical genomic investigations to date have identified rare copy number variants (CNVs, i.e. genomic microdeletions or microduplications $>1 \mathrm{~kb}$ ) considered pathogenic for neurodevelopmental disorders (NDD), including schizophrenia (SCZ), autism spectrum disorder (ASD), and intellectual disability (ID). ${ }^{1-3}$ Initial genomic studies of CNVs in NDD utilized chromosomal microarray analyses, while most recent discovery and validation efforts have leveraged genome-wide association analyses (GWAS), with CNVs called from genotyping arrays. $^{2-6}$ Among NDD-pathogenic CNVs, eight CNVs are reported to occur at significantly increased frequencies in schizophrenia compared to controls, including the $22 q 11.2$ deletion underlying velocardiofacial syndrome, which is among the most well-studied and clinically characterized.2, 7 Nearly all NDD-CNVs have a greater effect on disease risk compared to common genetic variants. For example, the reported odds ratios (OR) of schizophreniaassociated-CNVs range from 3-60, whereas the OR conferred by most GWAS-significant single nucleotide polymorphisms (SNP) is less than $1.2 .^{2,8}$ NDD-pathogenic CNVs have been characterized in clinical studies and population cohorts, to quantify clinical features of developmental delay, physical stigmata and neuropsychiatric effects, and have been established as both inherited and de novo risk factors. ${ }^{9-12}$ 
medRxiv preprint doi: https://doi.org/10.1101/2021.06.09.21258554; this version posted June 12, 2021. The copyright holder for this preprint (which was not certified by peer review) is the author/funder, who has granted medRxiv a license to display the preprint in perpetuity.

It is made available under a CC-BY 4.0 International license .

Despite considerable investigation of NDD-pathogenic CNVs to date, significant gaps in their clinical characterization remain. First, pleiotropy, or non-specificity of NDD-pathogenic CNVs remains unexplained, that is the same CNV may confer risk for multiple neurodevelopmental disorders. ${ }^{13}$ Second, the variable penetrance and expressivity remain poorly understood, that is among NDD-CNV carriers, developmental or neuropsychiatric symptomatology ranges from unaffected to severely affected. ${ }^{14}$ Some studies suggest a role of 'background' genetic risk, polygenic risk derived from common risk alleles, in interacting with NDD-pathogenic CNVs to influence penetrance; in other reports, there is evidence of a 'two-hit' model whereby a large NDDCNV event exacerbated neurodevelopmental phenotypes, in association with other large deletions or duplications. ${ }^{15-18}$ Most clinical reports of NDD-CNVs to date have focused on neuropsychiatric traits, absent overall medical co-morbidities. Lastly, most population cohorts/registries, or large-scale biobank studies to date of CNVs have been limited to European ancestry, limiting overall clinical generalizability. ${ }^{19-22}$

The precise pathogenic factor within many NDD-pathogenic CNV regions remains unknown, whether gene dosage effect of protein-coding gene(s), non-coding species (i.e., microRNA) or other modifying, regulatory factors. ${ }^{23,24}$ Further investigation of CNV carriers may elucidate not only underlying biological factors or mechanisms of pathogenesis, but also accelerate potential translation efforts and more precise therapeutic strategies.

Clinical investigation of CNV carriers is challenging however, given their rare frequency and requisite access to large-scale clinical and genetic resources, concurrently. Several research consortia focus on individual CNVs (i.e., 22q11 deletion, 3q29 deletion or 16p11.2), while other consortia focus on CNVs in aggregate, for example the Deciphering Developmental Disorders project or Enhancing Imaging Genetics through Meta-Analysis (ENIGMA-CNV), the latter investigating neuroimaging outcomes. ${ }^{25-27}$ The study of multiple NDD-pathogenic CNVs is 
medRxiv preprint doi: https://doi.org/10.1101/2021.06.09.21258554; this version posted June 12, 2021. The copyright holder for this preprint (which was not certified by peer review) is the author/funder, who has granted medRxiv a license to display the preprint in perpetuity.

It is made available under a CC-BY 4.0 International license .

advantageous since it permits inter-CNV comparison and assessment of composite clinical outcomes.

The current study leveraged a robust clinical genetics resource, the "BioMe" biobank, a genetics repository linked to the electronic health records (EHR) of approximately 25,000 individuals recruited across medical specialties and across ancestry and socio-economic background. ${ }^{28,29}$ Notably, the BioMe biobank is multi-ancestry, enabling diverse query across ancestry (in contrast to most biobanks studies to date, which have focused primarily on European ancestry). In a forward genetics approach, individuals harboring NDD-pathogenic CNVs were identified without phenotypic ascertainment bias, followed by a series of novel in-silico clinical assessments. The genetics repository of the biobank enabled the identification of individuals whom harbor NDDCNVs, while the EHR data enabled investigation of clinical indices, including diagnostic codes, laboratory serum tests, and clinical descriptive data contained within documented encounters.

\section{METHODS}

\section{"BioMe" Biobank}

Participants were recruited throughout the Mount Sinai healthcare system, as per a protocol approved by the local Institutional Review Board (IRB), initiated in 2007. Participants were recruited across age and ancestry, and from clinics throughout the healthcare system of diverse medical and neuropsychiatric specialty (See Supplementary Table 1, Supplementary Methods). In providing informed consent, Biobank participants authorized access to their de-identified healthcare records and also donated a blood sample for extraction of genetic material for research purposes. As per the approved protocol, no disclosure/feedback of genetic results would be provided, as the analyses were for research purposes. Participants were offered the option to consent to be re-contacted for future research studies. 
medRxiv preprint doi: https://doi.org/10.1101/2021.06.09.21258554; this version posted June 12, 2021. The copyright holder for this preprint (which was not certified by peer review) is the author/funder, who has granted medRxiv a license to display the preprint in perpetuity.

It is made available under a CC-BY 4.0 International license.

\section{Sample Genotyping and Exome Sequencing}

As previously described, BioMe biobank participants were genotyped on the Illumina Global Screening Array (GSA-24v1.0) and exome sequencing was performed at the Regeneron Genetics Center. ${ }^{29}$ (See Supplementary Methods for details of genotyping and exome sequencing QC and filtering).

\section{CNV Calling}

The 64 CNVs called in the current analysis, herein termed "NDD-CNVs", were reported in previous biobank reports (i.e., UK Biobank and Geisinger DiscoverEHR), described as set of CNVs 'pathogenic' for neurodevelopment disorders (NDD), culled from 92 CNVs in 47 genomic locations, including reciprocal deletions/duplications. ${ }^{5,6,19,20} 30,31$ A CNV was called based on the union, or consensus of two CNV calling algorithms (each using a different type of sequence data), a whole exome-sequenced based method, Lattice-Aligned Mixture Models (CLAMMS), and a genotype array-based method, PennCNV. (See Supplementary Methods for details of each CNV calling method, QC and filtering). ${ }^{32,33}$ Only BioMe samples with both WES-based CLAMMS calls and array-based PennCNV calls, subsequent to QC ( $n=24,877$ samples) were included in NDDCNV analyses and downstream phenotypic enrichment and association analyses (See Supplementary Methods). As per previous biobank reports, individuals were designated as positive for a CNV, if breakpoints overlapped at least $50 \%$ of the defined critical region, and for single gene CNV deletions (i.e., NRXN1 deletions) intersected at least one exon. ${ }^{19,20}$

\section{Enrichment for Neuropsychiatric Disorders}

For enrichment analyses, samples without phenotype data were excluded, as well as samples with less than two clinical encounters, to increase the reliability of phenotypic analyses, yielding $n=22,279$ individuals for the analyses of enrichment of neuropsychiatric disorders. A Fisher's exact test was applied to test for statistical significance of enrichment of an aggregate, set of rare, 
medRxiv preprint doi: https://doi.org/10.1101/2021.06.09.21258554; this version posted June 12, 2021. The copyright holder for this preprint (which was not certified by peer review) is the author/funder, who has granted medRxiv a license to display the preprint in perpetuity.

It is made available under a CC-BY 4.0 International license .

NDD-CNVs (excluding the common 15q11.2 del/duplication) for neurodevelopmental and neuropsychiatric disease categories.

\section{Phenome-Wide Association Analyses ("PheWAS")}

To reduce potential confounding effects of relatedness, a random individual from each related pair with more than second-degree relatedness (kinship coefficient $>0.0885$ ) was excluded, as estimated based on genotype data (See Supplementary Methods).

PheWAS was conducted using 'REGENIE', a machine-learning method, especially developed for rare variant analysis of binary (case-control) traits with unbalanced case-control ratios. ${ }^{34}$ International Classification of Diseases codes (ICD9 and ICD10) were mapped to hierarchicallyclustered 'phecodes' and for each phecode, the number of cases and controls determined, longitudinally, with a case defined as at least 2 counts, a control as 0 , while a count of 1 were set to missing for the phecode. ${ }^{35,36}$ Phecodes were filtered for a minimum of 100 cases for each ancestry-stratified group, European, African, and Hispanic, to ensure robust analyses, so that only the more prevalent $n=195$ phecodes, of 1,736 phecodes across the biobank cohort, were tested in the current NDD-CNV PheWAS (See Supplementary Methods). Using REGENIE, each phecode was regressed onto CNV (binary) status with covariates of: age, sex, ancestry, principal components (PCs) 1-5 of the genotype data, and density of electronic health records (See Supplementary Methods). For each PheWAS conducted using REGENIE, Bonferroni-correction was applied to control for multiple testing. In addition to ancestry-stratified analyses, multiancestry meta-analysis, was conducted using METAL ${ }^{37}$ 
medRxiv preprint doi: https://doi.org/10.1101/2021.06.09.21258554; this version posted June 12, 2021. The copyright holder for this preprint (which was not certified by peer review) is the author/funder, who has granted medRxiv a license to display the preprint in perpetuity.

It is made available under a CC-BY 4.0 International license .

\section{Association Analyses with Quantitative Outcome}

Median BMI and serum lab values were inverse normal transformed, and regressed onto NDDCNV status (binary variable), adjusting for covariates of age, sex, ancestry, PCs 1-5 of the genotype data, and density of electronic health records (See Supplementary Methods).

\section{RESULTS}

The BioMe biobank cohort utilized in the current CNV study ( $n=24,877$ individuals) is multiancestry (31.7\% European, 24\% African, 34.3\% Hispanic, 10\% Other), consisting of a range of ages at enrollment, but skewed towards older adults (mean age at enrollment: 50.3 years), with few pediatric participants $(2.5 \%<18$ years $)$, and more women $(59 \%)$ than men (Table 1$)$. To initiate the current investigation, individuals harboring NDD-CNVs (any of 64 NDD-CNVs) were identified within the "BioMe" Biobank.

\section{CNV Prevalence}

CNVs were called from the consensus of two CNV calling algorithms, a whole exome sequencingbased method (CLAMMS), and a genotype array-based method, PennCNV, yielding the result that $2.5 \%$ of individuals ( $\mathrm{n}=627$ individuals) within the biobank harbor a NDD-CNV (Table 2$).{ }^{32,33}$

Prevalence varied by CNV locus and type, notable for six highly-prevalent CNVs: chr15q11.2 deletion and duplication, chr2q13(NPHP1) deletion and duplication, chr15q13.3 (CHRNA7) duplication, and chr16p13.11 duplication (Supplementary Table 2). Only one carrier of the 22q11.2 hemizygous deletion was identified, and for $21 \mathrm{CNVs}$, there were no carriers identified (i.e., chr15-PWS-DUP, chr17 Potocki-Lupski syndrome, 17q11.2(NF1)DEL). The prevalence for each NDD-CNV in BioMe is compared with previously-reported UK Biobank and DiscoverEHR CNV analyses (Supplementary Table 2). 19,20 
medRxiv preprint doi: https://doi.org/10.1101/2021.06.09.21258554; this version posted June 12, 2021. The copyright holder for this preprint (which was not certified by peer review) is the author/funder, who has granted medRxiv a license to display the preprint in perpetuity.

It is made available under a CC-BY 4.0 International license .

Overall, within the biobank cohort, the demographic variables of age, sex and ancestry, did not differ significantly for the subset of NDD-CNV carriers, compared to individuals without NDDCNVs (Table 1). In addition to the multi-ancestry composition, a notable demographic feature of the NDD-CNV carriers is the mean of 50 years of age, similar to the overall BioMe cohort. Therefore, in the current analysis, NDD-CNVs were not surveyed in a childhood or developmental context, specifically, but rather mostly in older adults. In assessing relatedness among NDD-CNV carriers, 99 pairs of relatives of at least second-degree were identified: 17 pairs in whom both relatives harbored NDD-CNVs, and 82 pairs in which one, but not both relatives, harbored a NDDCNV (Supplementary Table 3). Furthermore, among NDD-CNV carriers within the biobank, $n=20$ individuals harbored two NDD-CNVs, each.

\section{Enrichment of Neuropsychiatric Disorders}

Next, individuals harboring rare, NDD-CNVs were tested for enrichment of neurodevelopmental disorders (Table 3, Supplementary Table 4 and Supplementary Methods). The aggregate set of NDD-CNV carriers $(n=376)$ were enriched for congenital disorders (Fisher's exact two-sided $p$ value $=0.02$, OR=1.8), but not schizophrenia $(p=1)$ nor seizure disorder $(p=1)$. In ancestry-stratified analyses of congenital disorders, NDD-CNVs were not enriched among the major three ancestry subgroups (European $p=1$, African $p=0.16$, Hispanic $p=0.13$ ) but significant for the 'other' ancestry subgroup ( $p$-value $=0.005, \mathrm{OR}=6.9$ ) but with a wide-ranging $95 \%$ confidence interval, owing to small group size ( $n=54$ combined Asian, Native American and other).

Enrichment for ASD/ID trended towards significance $(p=0.09)$ but with notably few cases represented in BioMe; within the BioMe cohort, the prevalence of childhood developmental disorders is markedly low (BioMe ASD/ID prevalence=0.13\%) owing to few pediatric participants, compared to adult-onset disorders, which better approximate overall population prevalence (i.e. BioMe SCZ prevalence=1.1\%). 
medRxiv preprint doi: https://doi.org/10.1101/2021.06.09.21258554; this version posted June 12, 2021. The copyright holder for this preprint (which was not certified by peer review) is the author/funder, who has granted medRxiv a license to display the preprint in perpetuity.

It is made available under a CC-BY 4.0 International license.

Enrichment for adult-onset mood disorders was also queried, and NDD-CNVs were found to be enriched for major depressive disorder (MDD) (Fisher's exact two-sided $p$-value=0.04, OR=1.3) with the enrichment for MDD driven by individuals of African ancestry (two-sided p-value $=0.01$, $\mathrm{OR}=1.8$ ). In contrast, there was no NDD-CNV enrichment for bipolar disorder (two-sided $p$ value $=0.83$ )

\section{Association with ICD-Diagnosis Codes ('PheWAS')}

To investigate phenotypic associations in the biobank broadly, beyond neuropsychiatric disorders, an agnostic phenome-wide association ("PheWAS") was next applied, to test NDDCNV association with ICD codes, coded medical diagnoses across organ systems. ${ }^{38,39}$ Here, PheWAS tested 195 hierarchically-clustered ICD codes (i.e. 'phecodes") for association with each of five NDD-CNV sets, (1) an aggregated set of rare, NDD-CNVs ( $n=225$, excluding $15 q 11.2$ deletion/duplication and 2q13(NPHP1) deletion/duplication), and prevalent, individual NDDCNVs: (2) 15q13.3 duplication (CHRNA7) ( $\mathrm{n}=36) ;$ (3) 16p13.11 duplication ( $\mathrm{n}=34)$; (4) 2q13(NPHP1) deletion ( $n=63) ;(5)$ 2q13(NPHP1) duplication $(n=53)$. Each NDD-CNV PheWAS was stratified by ancestry (European, African, Hispanic), as well as combined in a multi-ancestry meta-analysis.

Overall, PheWAS across the NDD-CNV sets, yielded several significant associations (Figure 1). The aggregated set of rare, NDD-CNVs were significantly associated with 'Obstructive sleep apnea' (Z-score=3.6, $p=3.24 \times 10-4)$ and 'Urinary tract infection' (Z-score=3.5, $p=4.4 \times 10-4)$, while subthreshold association was noted with 'essential hypertension' (Z-score=-3.00, $p=0.003)$ and 'acute renal failure $(Z-s c o r e=2.8, p=0.006)$ (Figure 1, Supplementary Table 7).

In ancestry-meta-analysis of individual NDD-CNV loci, the 16p13.11 duplication was significant for association with 'congestive heart failure; non-hypertensive' (Z-score=4.1, $p=3.38 \times 10^{-5}$ ) 
medRxiv preprint doi: https://doi.org/10.1101/2021.06.09.21258554; this version posted June 12, 2021. The copyright holder for this preprint (which was not certified by peer review) is the author/funder, who has granted medRxiv a license to display the preprint in perpetuity.

It is made available under a CC-BY 4.0 International license .

(Figure 1, Supplementary Table 8). In addition, in ancestry-stratified analyses, European-specific PheWAS was significant for association of $15 q 13.3$ duplication (CHRNA7) with 'disorders of vitreous body' $\left(p=1.02 \times 10^{-6}\right)$, 'acute pharyngitis' $\left(p=1.05 \times 10^{-5}\right)$, and 'stiffness of joint' $\left(p=1.9 \times 10^{-}\right.$ $\left.{ }^{4}\right)$. Hispanic-specific PheWAS was significant for association of 15q13.3 duplication (CHRNA7) and 'diseases of the larynx and vocal cords' $\left(p=4.9 \times 10^{-7}\right)$ and 'diseases of hair and hair follicles' $\left(p=4.2 \times 10^{-4}\right) .($ Supplementary Table 9$)$

\section{Association with Clinical Indices (BMI and Lab Values)}

Further, we investigated the association of rare NDD-CNVs, in aggregate, with quantitative clinical outcomes, body mass index (BMI) and common serum lab values. The set of all rare, NDD-CNVs (excluding the more common 15q11.2 del/dup and $2 q 13$ NPHP1 del/dup) was found to be associated with increased BMI ( $n=215$ CNV carriers, Beta $=0.14, p=0.04)$ (Supplementary Table 9). Interestingly, as per the ancestry-stratified analyses, for the Hispanic NDD-CNV carriers there was an association of increased BMI with NDD-CNV status $(n=74$, Beta $=0.30, p=0.004)$, but not for NDD-CNV carriers of African-American $(n=75$, Beta $=0.02, p=0.89)$ nor European ancestries $(n=66$, Beta $=0.02, p=0.83)$. Of note, the rare, $16 p 11.2$ deletion (associated with BMI in past reports) was found to be distributed among ancestries ( $n=3$ African-American carriers, $n=4$ European carrier, $\mathrm{n}=2$ Hispanic carriers). ${ }^{40}$

For serum lab test associations, the aggregated rare, NDD-CNV set was tested for association with 38 common serum lab tests, given their widespread medical utility, including comprehensive metabolic panel, complete blood count and lipid profile tests, that are routinely performed across inpatient and outpatient clinics (Supplementary Table 10). Among the multi-ancestry NDD-CNV carriers, tested in aggregate, there were no significant associations after multiple testing correction. 
medRxiv preprint doi: https://doi.org/10.1101/2021.06.09.21258554; this version posted June 12, 2021. The copyright holder for this preprint (which was not certified by peer review) is the author/funder, who has granted medRxiv a license to display the preprint in perpetuity.

It is made available under a CC-BY 4.0 International license .

\section{DISCUSSION}

In the current study, individuals who harbor rare CNVs that are known risk factors for neurodevelopmental disorders, were identified within the BioMe biobank and their clinical presentation surveyed in biobank-based analyses. The leveraged biobank is advantageous in its multi-ancestry composition and robust clinical data repository. Overall, as per the consensus of two CNV calling algorithms, $2.5 \%$ of individuals within BioMe, harbor at least one of 64 NDDCNVs. Ancestry distribution of individuals whom harbored NDD-CNVs was comparable to the ancestry distribution of the biobank, overall ( 1/3 European and $\sim 1 / 4$ African). Further, 21 NDDCNVs did not have any carriers within BioMe. The prevalence of individual, rare NDD-CNVs varied in comparison to previous biobank reports, of the UKBB and Geisinger DiscoverEHR, by CNV locus. ${ }^{19,20}$ The most highly-prevalent NDD-CNVs in BioMe, were also identified as most highly-prevalent in other reports (i.e. 15q11.2deletion/duplication, chr2q13(NPHP1) deletion/duplication). As compared to the Discover EHR cohort, the same NDD-CNVs that had no carriers in DiscoverEHR also had no carriers in BioMe.

In comparing the current analysis of NDD-CNVs in BioMe with previous biobank reports, the divergence in ancestry is most notable, as the UKBB and Geisinger DiscoverEHR cohorts are nearly exclusively of European ancestry (i.e. DiscoverEHR: 98\% European ancestry), while BioMe is markedly multi-ancestry. Of further divergence, the UKBB was formed with an intention to recruit a 'healthy cohort', in contrast to BioMe, recruiting from within a medical system. Overall, the BioMe biobank is affected by ascertainment bias (i.e. , $67 \%$ recruited from outpatient medicine clinics), as is any biobank, an important caveat in considering biobank comparisons.

Within BioMe there is a skew towards older adults with few pediatric participants. The advanced age range presented an opportunity for broad clinical assessment. Indeed, many investigations of NDD-CNVs to date, including their initial discovery, have focused on early-childhood 
medRxiv preprint doi: https://doi.org/10.1101/2021.06.09.21258554; this version posted June 12, 2021. The copyright holder for this preprint (which was not certified by peer review) is the author/funder, who has granted medRxiv a license to display the preprint in perpetuity.

It is made available under a CC-BY 4.0 International license .

developmental deviation, without consideration of longitudinal illness trajectory. Of note, the healthcare system from which BioMe is derived is not a single-provider, contained system; rather, participants may receive care from other systems. For example, individuals may present to BioMe as an adult, having received care elsewhere as a child/adolescent, or may present for specialty medical care, having received psychiatric care elsewhere. Further, EHR data incorporated in the current analysis dates to 2003-2004, limiting direct, early-life analyses for most adults in the current study.

These challenges of biobank analyses, notwithstanding, the current BioMe analyses yielded interesting and notable findings. Among NDD-CNV carriers, there was a significant enrichment for congenital disorders, confirming previous reports. ${ }^{5,6,19}$ Major depressive disorder (MDD) was also found to be significantly enriched, addressing in part, conflicting, past reports about the enrichment of NDD-CNVs in major depressive disorder. ${ }^{41,42}$ In contrast to the UKBB finding of enrichment of MDD in the cohort of European ancestry, however, the current BioMe analysis yielded enrichment of MDD among individuals of African ancestry, but not Hispanic or European. ${ }^{41}$ The current study used a filtering criteria of at least 2 ICD codes assigned to validate a diagnosis, and a minimum engagement of two clinical encounters, but overall the validity of ICD codes as a proxy for neuropsychiatric diagnosis warrants ongoing assessment in BioMe and other biobanks. Future studies may incorporate phenotyping algorithms, computational tools to mine EHR clinical descriptive data, to identify affected NDD cases, as has been developed for mood disorders. ${ }^{43}$

A previous UKBB analysis tested 58 phenotypes for individual NDD-CNV associations, identifying 46 associations (at FDR threshold of 0.1 ), including among the most common, obesity, hypertension, and renal failure. ${ }^{20}$ The current BioMe analysis tested an expanded set of 195 phenotypes for association, replicating the UKBB analysis in part, identifying top-most, subthreshold enrichment for hypertension and renal failure for the aggregate, rare NDD-CNV set. 
medRxiv preprint doi: https://doi.org/10.1101/2021.06.09.21258554; this version posted June 12, 2021. The copyright holder for this preprint (which was not certified by peer review) is the author/funder, who has granted medRxiv a license to display the preprint in perpetuity.

It is made available under a CC-BY 4.0 International license .

Furthermore, the current analysis identified a significant association of the aggregate, rare NDDCNV set with obstructive sleep apnea (a phenotype not tested in the UKBB analysis), for which obesity is the major risk factor. ${ }^{44}$ The current analysis also identified association of $16 \mathrm{p} 13.11$ duplication with congestive heart failure (non-hypertensive), and indeed, case reports of 16p13.11 microduplication indicate increased incidence of congenital heart defects and heart disease. ${ }^{45}$ Other ancestry-specific findings of the 15q13.3 (CHRNA7) duplication, eye disorders in individuals of European ancestry, and disease of the larynx and vocal cords in individuals of Hispanic ancestry, are phenotypes not tested in the previous UKBB analysis, nor have they been widely reported to date in $15 q 13.3$ microduplication in pediatric cases, but may warrant further investigation. $^{46}$

For the aggregate set of NDD-CNVs, there was a significant association with increased BMI, in a multi-ancestry analysis, and further, and an ancestry-specific finding of BMI association among individuals of Hispanic ancestry. While the $16 \mathrm{p} 11.2$ deletion is a well-characterized risk factor for obesity, this further implicates the potential role of other NDD-CNVs in obesity. ${ }^{47}$ For 38 common, serum lab tests, including blood count and blood chemistry, there was no identified significant association with the aggregate set of NDD-CNVs. ${ }^{40}$

A limitation of the current analysis is that due to the rarity of NDD-CNVs, the analyses combined NDD-CNVs across loci to ensure well-powered associations, but pooling may dilute the heterogeneity of the effects of individual CNVs. Further, though each CNV was selected based on previous biobank reports as per 'pathogenicity' criteria defined by American College of Medical Genetics standards, the strength of evidence varies by NDD-CNV locus. ${ }^{30,31}$ The associations with quantitative indices were limited to median BMI and serum lab values as outcome measures, but models using generalized linear mixed models may better fit longitudinal biobank data, which can extend over many years with repeated measurements. The current analyses employed select 
medRxiv preprint doi: https://doi.org/10.1101/2021.06.09.21258554; this version posted June 12, 2021. The copyright holder for this preprint (which was not certified by peer review) is the author/funder, who has granted medRxiv a license to display the preprint in perpetuity.

It is made available under a CC-BY 4.0 International license .

strategies to control for some variables within the EHR (i.e., threshold of number of clinical encounters for inclusion, covarying for density of electronic health records, use of REGENIE method for case/control imbalance), but further methodological innovations and strategies specific to large-scale, biobank analyses may be incorporated as they continue to emerge. ${ }^{48}$

Future recall of individual NDD-CNV carriers may permit detailed clinical measurements beyond EHR-based outcomes, including retrospective, childhood/developmental history, neurocognitive assessments or neuroimaging. The role of other NDD-associated genetic variants may be investigated in future biobank investigations, namely exome sequencing variants (SNVs). In addition, genome-wide CNV burden, the investigation of other genomic CNVs, may further illuminate their role in influencing NDD or NDD-related phenotypes and clinical outcomes. The role of 'background' polygenic risk in influencing penetrance, or NDD-case status, is critical, albeit limited in the current multi-ancestry study, as there is a disparity in polygenic risk scores, most derived initially from European cohorts, with trans-ethnic polygenic scores, only recently emerging, and of smaller scale. ${ }^{49}$

Ongoing large-scale, clinical genetic investigations as herein described, based on genetic stratification (i.e., 'precision psychiatry'), may lead to translational opportunities, clinical insights of at-risk individuals, as well as novel therapeutic strategies targeting specific genetic variants. The importance of diverse inclusion within biobanks and considering the effect of rare, genetic variants in a multi-ancestry context, is evident. 
medRxiv preprint doi: https://doi.org/10.1101/2021.06.09.21258554; this version posted June 12, 2021. The copyright holder for this preprint (which was not certified by peer review) is the author/funder, who has granted medRxiv a license to display the preprint in perpetuity.

It is made available under a CC-BY 4.0 International license .

Table 1: BioMe Biobank Demographic Overview: Demographics of biobank participants included in current analysis $(n=24,877)$ and subset harboring NDD-CNVs $(n=627)$

\begin{tabular}{|c|c|c|c|c|}
\hline & & $\begin{array}{c}\text { BioMe Biobank } \\
(\mathbf{n = 2 4 , 8 7 7 )}\end{array}$ & $\begin{array}{c}\text { BioMe Biobank } \\
\text { NDD-CNV } \\
(\mathbf{n = 6 2 7})\end{array}$ & p-value \\
\hline \multirow{3}{*}{ ANCESTRY } & European & $31.7 \%$ & $33.2 \%$ & 0.46 \\
\cline { 2 - 5 } & African & $24.0 \%$ & $26.8 \%$ & 0.10 \\
\cline { 2 - 5 } & Hispanic & $34.3 \%$ & $31.9 \%$ & 0.21 \\
\cline { 2 - 5 } & Other & $9.9 \%$ & $8.1 \%$ & 0.15 \\
\hline AGE & Mean Years (sd) & $50.5(17.3)$ & $50.4(17.0)$ & 0.87 \\
\hline & Age $<18$ Years & $2.5 \%$ & $2.4 \%$ & 0.09 \\
\hline SEX & Female & $58.7 \%$ & $62 \%$ & \\
\hline
\end{tabular}

Notes: $p$-value is derived from chi-square test for categorical variables (sex and ancestry), and two-sided t-test for age, comparing individuals with NDD-CNVs ( $n=627)$ and individuals without NDD-CNVs $(n=24,250)$. 
medRxiv preprint doi: https://doi.org/10.1101/2021.06.09.21258554; this version posted June 12, 2021. The copyright holder for this preprint (which was not certified by peer review) is the author/funder, who has granted medRxiv a license to display the preprint in perpetuity.

TABLE 2: NDD-CNVs in the "BioMe" Biobank: Each of 64 NDD-CNVs genotyped in the Biobank using a consensus of two CNV calling algorithms

\begin{tabular}{|c|c|c|c|c|}
\hline & LOCATION (hg19) & GENES (n) & BioMe (n) & PREVALENCE (\%) \\
\hline TAR_del & chr1:145,39-145,81 & 17 & 5 & 0.020 \\
\hline TAR_dup & chr1:145,39-145,81 & 17 & 18 & 0.072 \\
\hline $1 \mathrm{q} 21.1 \mathrm{del}$ & chr1:146,53-147,39 & 9 & 8 & 0.032 \\
\hline 1q21.1dup & chr1:146,53-147,39 & 9 & 3 & 0.012 \\
\hline NRXN1_del & chr2:50,14-51,26 & 1 & 3 & 0.012 \\
\hline $2 q 11.2 \mathrm{del}$ & chr2:96,74-97,68 & 22 & 2 & 0.008 \\
\hline 2q11.2dup & chr2:96,74-97,68 & 22 & 1 & 0.004 \\
\hline 2q13del(NPHP1) & chr2:110,86-110,98 & 3 & 81 & 0.326 \\
\hline 2q13dup(NPHP1) & chr2:110,86-110,98 & 3 & 62 & 0.249 \\
\hline $2 q 13$ del & chr2:111,39-112,01 & 3 & 3 & 0.012 \\
\hline 2q13dup & chr2:111,39-112,01 & 3 & 8 & 0.032 \\
\hline $2 \mathrm{q} 21.1 \mathrm{del}$ & chr2:131,48-131,93 & 5 & 9 & 0.036 \\
\hline 2q21.1dup & chr2:131,48-131,93 & 5 & 5 & 0.020 \\
\hline $3 q 29 \mathrm{del}$ & chr3:195,72-197,35 & 28 & 1 & 0.004 \\
\hline 3q29dup & chr3:195,72-197,35 & 28 & 0 & 0 \\
\hline Sotos $5 q 35 \mathrm{del}$ & chr5:175,72-177,05 & 39 & 0 & 0 \\
\hline $5 q 35$ dup & chr5:175,72-177,05 & 39 & 0 & 0 \\
\hline 7q11.23_del & chr7:72,74-74,14 & 26 & 1 & 0.004 \\
\hline WBS_7q11.23_dup & chr7:72,74-74,14 & 26 & 0 & 0 \\
\hline 7q11.23dup_distal & chr7:75,14-76,06 & 16 & 0 & 0 \\
\hline 8p23.1del & chr8:8,10-11,87 & 35 & 0 & 0 \\
\hline 8p23.1dup & chr8:8,10-11,87 & 35 & 0 & 0 \\
\hline $10 q 11.21 q 11.23 \mathrm{del}$ & chr10:49,39-51,06 & 19 & 1 & 0.004 \\
\hline 10q11.21q11.23dup & chr10:49,39-51,06 & 19 & 2 & 0.008 \\
\hline $10 q 23 \mathrm{del}$ & chr10:82,05-88,93 & 29 & 0 & 0 \\
\hline 10q23dup & chr10:82,05-88,93 & 29 & 1 & 0.004 \\
\hline 13q12del(CRYL1) & chr13:20,98-21,10 & 2 & 8 & 0.032 \\
\hline 13q12dup(CRYL1) & chr13:20,98-21,10 & 2 & 0 & 0 \\
\hline $13 q 12.12 \mathrm{del}$ & chr13:23,56-24,88 & 10 & 4 & 0.016 \\
\hline 13q12.12dup & chr13:23,56-24,88 & 10 & 9 & 0.036 \\
\hline $15 q 11.2 \mathrm{del}$ & chr15:22,81-23,09 & 5 & 60 & 0.241 \\
\hline 15q11.2dup & chr15:22,81-23,09 & 5 & 163 & 0.655 \\
\hline PW/AS_15q11.2q13.1 BP1-3_del & chr15:23,68-28,39 & 116 & 0 & 0 \\
\hline PW/AS_15q11.2q13.1 BP1-3_dup & chr15:23,68-28,39 & 116 & 0 & 0 \\
\hline 15q11q13del_BP3- & chr15:29,16-30,38 & 4 & 1 & 0.004 \\
\hline 15q11q13dup BP3- & chr15:29,16-30,38 & 4 & 3 & 0.012 \\
\hline 15q11q13dup_BP3-BP5 & chr15:29,16-32,46 & 17 & 0 & 0 \\
\hline $15 q 13.3 \mathrm{del}$ & chr15:31,08-32,46 & 8 & 5 & 0.020 \\
\hline $15 q 13.3$ dup & chr15:31,08-32,46 & 8 & 5 & 0.020 \\
\hline 15q13.3del(CHRNA7) & chr15:32,02-32,46 & 1 & 5 & 0.020 \\
\hline 15q13.3dup(CHRNA7) & chr15:32,02-32,46 & 1 & 42 & 0.169 \\
\hline $15 q 24 d e l$ & chr15:72,90-78,15 & 77 & 0 & 0 \\
\hline 15q24dup & chr15:72,90-78,15 & 77 & 0 & 0 \\
\hline $16 \mathrm{p} 13.11 \mathrm{del}$ & chr16:15,51-16,29 & 7 & 13 & 0.052 \\
\hline 16p13.11dup & chr16:15,51-16,29 & 7 & 39 & 0.157 \\
\hline 16p12.1del & chr16:21,95-22,43 & 8 & 2 & 0.008 \\
\hline 16p12.1dup & chr16:21,95-22,43 & 8 & 14 & 0.056 \\
\hline 16p11.2distal del & chr16:28,82-29,05 & 11 & 5 & 0.020 \\
\hline 16p11.2distal_dup & chr16:28,82-29,05 & 11 & 4 & 0.016 \\
\hline $16 \mathrm{p} 11.2 \mathrm{del}$ & chr16:29,65-30,20 & 30 & 15 & 0.060 \\
\hline 16p11.2dup & chr16:29,65-30,20 & 30 & 4 & 0.016 \\
\hline $17 \mathrm{p} 12 \mathrm{del}$ & chr17:14,14-15,43 & 8 & 6 & 0.024 \\
\hline 17p12dup & chr17:14,14-15,43 & 8 & 10 & 0.040 \\
\hline Smith Magenis & chr17:16,81-20,21 & 59 & 0 & 0 \\
\hline Potocki-Lupski & chr17:16,81-20,21 & 59 & 0 & 0 \\
\hline 17q11.2del(NF1) & chr17:29,12-30,27 & 19 & 0 & 0 \\
\hline 17q11.2dup(NF1) & chr17:29,12-30,27 & 19 & 0 & 0 \\
\hline $17 q 12$ del & chr17:34,81-36,22 & 17 & 4 & 0.016 \\
\hline 17q12dup & chr17:34,81-36,22 & 17 & 4 & 0.016 \\
\hline $17 q 21.31 \mathrm{del}$ & chr17:43,70-44,29 & 10 & 0 & 0 \\
\hline $22 q 11.2 \mathrm{del}$ & chr22:19,04-21,47 & 61 & 1 & 0.004 \\
\hline 22q11.2dup & chr22:19,04-21,47 & 61 & 7 & 0.028 \\
\hline 22q11.2distal_del & chr22:21,92-23,65 & 26 & 0 & 0 \\
\hline 22q11.2distal_dup & chr22:21,92-23,65 & 26 & 0 & 0 \\
\hline
\end{tabular}


medRxiv preprint doi: https://doi.org/10.1101/2021.06.09.21258554; this version posted June 12, 2021. The copyright holder for this preprint (which was not certified by peer review) is the author/funder, who has granted medRxiv a license to display the preprint in perpetuity.

It is made available under a CC-BY 4.0 International license.

TABLE 3: Enrichment for Neurodevelopmental/Neuropsychiatric Disorders: Among carriers of NDDCNVs, enrichment for neurodevelopmental and neuropsychiatric disorders

\begin{tabular}{|c|c|c|c|c|}
\hline (NEURO)DEVELOPMENTAL DISORDER & $\mathbf{n}$ & $\mathbf{p}$-value & OR & $\mathbf{9 5 \%} \mathbf{C l}$ \\
\hline SCZ/OTHER SCZ PSYCHOSIS & 412 & 1 & 0.9 & $0.3-1.9$ \\
\hline ASD/ID & 29 & 0.09 & 4.3 & $0.5-17.3$ \\
\hline CONGENITAL DISORDERS & 639 & 0.02 & 1.8 & $1.1-2.9$ \\
\hline EPILEPSY/SEIZURE & 342 & 1 & 0.9 & $0.3-2.1$ \\
\hline
\end{tabular}

\begin{tabular}{|c|c|c|c|c|}
\hline ADULT-ONSET NEUROPSYCHIATRIC DISORDER & $\mathbf{n}$ & $\mathbf{p}$-value & OR & $\mathbf{9 5 \%} \mathbf{C l}$ \\
\hline BIPOLAR DISORDER & 329 & 0.83 & 1.08 & $0.4-2.4$ \\
\hline MAJOR DEPRESSIVE DISORDER & 3668 & 0.04 & 1.31 & $1-1.7$ \\
\hline
\end{tabular}

Notes:

-SCZ: schizophrenia; ASD: Autism Spectrum Disorders; ID: Intellectual Disability -See Supplementary Table 4 for description of each disorder, by ICD code, and for tabulation of NDD-CNVs tested. -Fisher's exact test for NDD CNV enrichment, by disorder, reported two-sided p-value, OR, 95\% Cl indicated. 
medRxiv preprint doi: https://doi.org/10.1101/2021.06.09.21258554; this version posted June 12, 2021. The copyright holder for this preprint (which was not certified by peer review) is the author/funder, who has granted medRxiv a license to display the preprint in perpetuity.

It is made available under a CC-BY 4.0 International license.

FIGURE 1: NDD-CNV PheWAS Multi-ancestry, Meta-analysis: Manhattan plots of PheWAS results for multi-ancestry, meta-analysis for: All NDD-CNVs (excluding 15q11.2 del/dup,2q13(NPHP1) del/dup) and most prevalent, individual CNVs (a) 15q13.3 (CHRNA7)dup; (b) 16p13.11dup; (c) 2q13(NPHP1)del and (d) 2q13(NPHP1) dup.

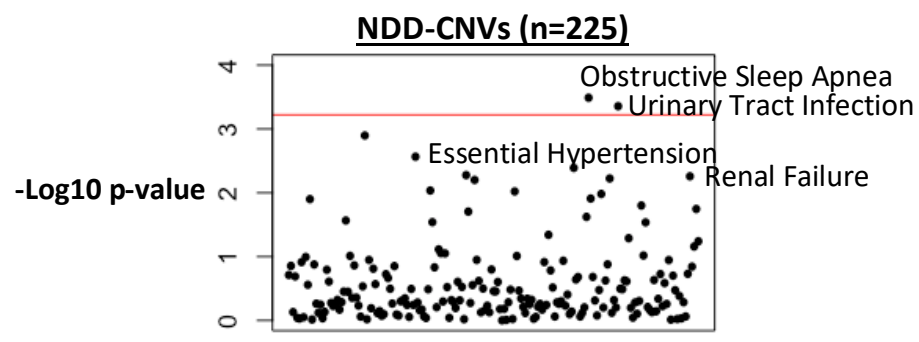

(a) 15q13.3 (CHRNA7) dup ( $\mathrm{n}=36)$

(b) CNV 16p13.11 dup ( $n=34)$

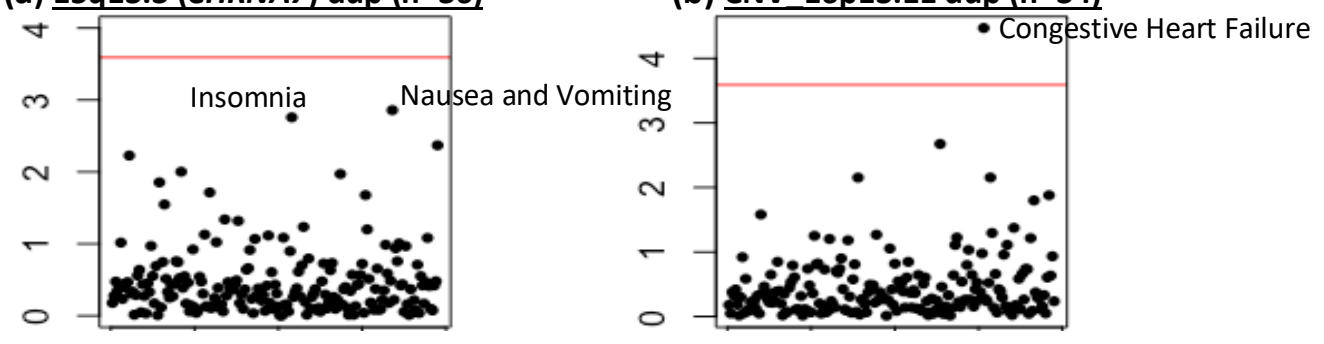

-Log10 p-value

(c) $12 q 13($ NPHP1) del $(n=63)$

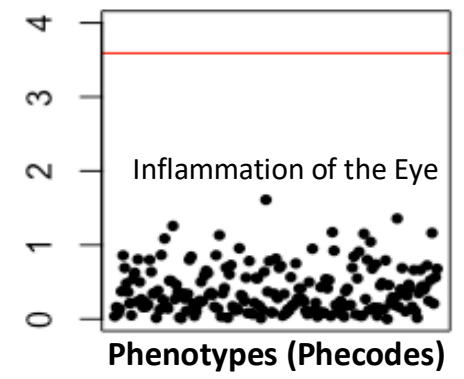

(d) $2 q 13(N P H P 1)$ dup $(n=53)$

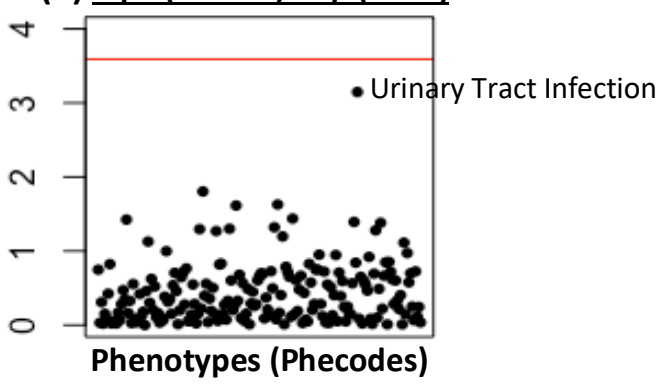

Notes:

-For each Manhattan plot, 195 ICD-based phecodes are on $x$-axis, $y$-axis is - $\log 10$ (p-value) -Red horizontal line represents the Benjamini-Hochberg FDR $=0.05$ significance threshold -See Supplementary Table 7 and Supplementary Table 8 for detailed PheWAS results, that are depicted in Manhattan plots. 
medRxiv preprint doi: https://doi.org/10.1101/2021.06.09.21258554; this version posted June 12, 2021. The copyright holder for this preprint (which was not certified by peer review) is the author/funder, who has granted medRxiv a license to display the preprint in perpetuity.

It is made available under a CC-BY 4.0 International license.

\section{REFERENCES}

1. Sebat J, Lakshmi B, Malhotra D, Troge J, Lese-Martin C, Walsh T, et al. Strong association of de novo copy number mutations with autism. Science. 2007;316(5823):445-9.

2. Marshall CR, Howrigan DP, Merico D, Thiruvahindrapuram B, Wu W, Greer DS, et al. Contribution of copy number variants to schizophrenia from a genome-wide study of 41,321 subjects. Nat Genet. 2017;49(1):27-35.

3. Pinto D, Delaby E, Merico D, Barbosa M, Merikangas A, Klei L, et al. Convergence of genes and cellular pathways dysregulated in autism spectrum disorders. Am J Hum Genet. 2014;94(5):677-94.

4. Cooper GM, Coe BP, Girirajan S, Rosenfeld JA, Vu TH, Baker C, et al. A copy number variation morbidity map of developmental delay. Nat Genet. 2011;43(9):838-46.

5. Coe BP, Witherspoon K, Rosenfeld JA, van Bon BWM, Vulto-van Silfhout AT, Bosco P, et al. Refining analyses of copy number variation identifies specific genes associated with developmental delay. Nature Genetics. 2014;46(10):1063-71.

6. Dittwald P, Gambin T, Szafranski P, Li J, Amato S, Divon MY, et al. NAHR-mediated copy-number variants in a clinical population: mechanistic insights into both genomic disorders and Mendelizing traits. Genome research. 2013;23(9):1395-409.

7. Tang SX, Gur RE. Longitudinal perspectives on the psychosis spectrum in 22q11.2 deletion syndrome. Am J Med Genet A. 2018;176(10):2192-202.

8. Biological insights from 108 schizophrenia-associated genetic loci. Nature. 2014;511(7510):421-7.

9. Swaminathan GJ, Bragin E, Chatzimichali EA, Corpas M, Bevan AP, Wright CF, et al. DECIPHER: web-based, community resource for clinical interpretation of rare variants in developmental disorders. Hum Mol Genet. 2012;21(R1):R37-44.

10. Owen D, Bracher-Smith M, Kendall KM, Rees E, Einon M, Escott-Price V, et al. Effects of pathogenic CNVs on physical traits in participants of the UK Biobank. BMC Genomics. 2018;19(1):867.

11. Kendall KM, Bracher-Smith M, Fitzpatrick H, Lynham A, Rees E, Escott-Price V, et al. Cognitive performance and functional outcomes of carriers of pathogenic copy number variants: analysis of the UK Biobank. Br J Psychiatry. 2019;214(5):297-304.

12. Kendall KM, Rees E, Escott-Price V, Einon M, Thomas R, Hewitt J, et al. Cognitive Performance Among Carriers of Pathogenic Copy Number Variants: Analysis of 152,000 UK Biobank Subjects. Biol Psychiatry. 2017;82(2):103-10.

13. Malhotra D, Sebat J. CNVs: harbingers of a rare variant revolution in psychiatric genetics. Cell. 2012;148(6):1223-41.

14. Kirov G. CNVs in neuropsychiatric disorders. Hum Mol Genet. 2015;24(R1):R45-9.

15. Tansey KE, Rees E, Linden DE, Ripke S, Chambert KD, Moran JL, et al. Common alleles contribute to schizophrenia in CNV carriers. Molecular Psychiatry. 2016;21(8):1085-9.

16. Bergen SE, Ploner A, Howrigan D, O'Donovan MC, Smoller JW, Sullivan PF, et al. Joint Contributions of Rare Copy Number Variants and Common SNPs to Risk for Schizophrenia. Am J Psychiatry. 2019;176(1):29-35.

17. Girirajan S, Rosenfeld JA, Cooper GM, Antonacci F, Siswara P, Itsara A, et al. A recurrent 16p12.1 microdeletion supports a two-hit model for severe developmental delay. Nat Genet. 2010;42(3):203-9.

18. Pizzo L, Lasser M, Yusuff T, Jensen M, Ingraham P, Huber E, et al. Functional assessment of the "two-hit" model for neurodevelopmental defects in Drosophila and X. laevis. PLoS Genet. 2021;17(4):e1009112.

19. Martin CL, Wain KE, Oetjens MT, Tolwinski K, Palen E, Hare-Harris A, et al. Identification of Neuropsychiatric Copy Number Variants in a Health Care System Population. JAMA Psychiatry. 2020.

20. Crawford K, Bracher-Smith M, Owen D, Kendall KM, Rees E, Pardiñas AF, et al. Medical consequences of pathogenic CNVs in adults: analysis of the UK Biobank. J Med Genet. 2019;56(3):131-8.

21. Schmidt M, Schmidt SA, Sandegaard JL, Ehrenstein V, Pedersen L, Sørensen HT. The Danish National Patient Registry: a review of content, data quality, and research potential. Clin Epidemiol. 2015;7:449-90.

22. Männik K, Mägi R, Macé A, Cole B, Guyatt AL, Shihab HA, et al. Copy Number Variations and Cognitive Phenotypes in Unselected Populations. JAMA. 2015;313(20):2044-54. 
medRxiv preprint doi: https://doi.org/10.1101/2021.06.09.21258554; this version posted June 12, 2021. The copyright holder for this preprint (which was not certified by peer review) is the author/funder, who has granted medRxiv a license to display the preprint in perpetuity.

It is made available under a CC-BY 4.0 International license .

23. Qiao Y, Badduke C, Mercier E, Lewis SM, Pavlidis P, Rajcan-Separovic E. miRNA and miRNA target genes in copy number variations occurring in individuals with intellectual disability. BMC Genomics. 2013;14:544.

24. Warnica W, Merico D, Costain G, Alfred SE, Wei J, Marshall CR, et al. Copy number variable microRNAs in schizophrenia and their neurodevelopmental gene targets. Biol Psychiatry. 2015;77(2):158-66.

25. Sønderby IE, Gústafsson Ó, Doan NT, Hibar DP, Martin-Brevet S, Abdellaoui A, et al. Dose response of the $16 \mathrm{p} 11.2$ distal copy number variant on intracranial volume and basal ganglia. Molecular Psychiatry. 2020;25(3):584-602.

26. Firth HV, Wright CF. The Deciphering Developmental Disorders (DDD) study. Dev Med Child Neurol. 2011;53(8):702-3.

27. van der Meer D, Sonderby IE, Kaufmann T, Walters GB, Abdellaoui A, Ames D, et al. Association of Copy Number Variation of the 15q11.2 BP1-BP2 Region With Cortical and Subcortical Morphology and Cognition. JAMA Psychiatry. 2019:1-11.

28. Li L, Cheng WY, Glicksberg BS, Gottesman O, Tamler R, Chen R, et al. Identification of type 2 diabetes subgroups through topological analysis of patient similarity. Sci Transl Med. 2015;7(311):311ra174.

29. Abul-Husn NS, Soper ER, Odgis JA, Cullina S, Bobo D, Moscati A, et al. Exome sequencing reveals a high prevalence of BRCA1 and BRCA2 founder variants in a diverse population-based biobank. Genome Med. 2019;12(1):2.

30. Kearney HM, Thorland EC, Brown KK, Quintero-Rivera F, South ST, Committee AWGotACoMGLQA. American College of Medical Genetics standards and guidelines for interpretation and reporting of postnatal constitutional copy number variants. Genetics in Medicine. 2011;13(7):680-5.

31. Riggs ER, Andersen EF, Cherry AM, Kantarci S, Kearney H, Patel A, et al. Technical standards for the interpretation and reporting of constitutional copy-number variants: a joint consensus recommendation of the American College of Medical Genetics and Genomics (ACMG) and the Clinical Genome Resource (ClinGen). Genet Med. 2020;22(2):245-57.

32. Packer JS, Maxwell EK, O'Dushlaine C, Lopez AE, Dewey FE, Chernomorsky R, et al. CLAMMS: a scalable algorithm for calling common and rare copy number variants from exome sequencing data. Bioinformatics. 2016;32(1):133-5.

33. Wang K, Li M, Hadley D, Liu R, Glessner J, Grant SF, et al. PennCNV: an integrated hidden Markov model designed for high-resolution copy number variation detection in whole-genome SNP genotyping data. Genome Res. 2007;17(11):1665-74.

34. Mbatchou J, Barnard L, Backman J, Marcketta A, Kosmicki JA, Ziyatdinov A, et al. Computationally efficient whole genome regression for quantitative and binary traits. bioRxiv. 2020:2020.06.19.162354.

35. Wei WQ, Bastarache LA, Carroll RJ, Marlo JE, Osterman TJ, Gamazon ER, et al. Evaluating phecodes, clinical classification software, and ICD-9-CM codes for phenome-wide association studies in the electronic health record. PLoS One. 2017;12(7):e0175508.

36. Wu P, Gifford A, Meng X, Li X, Campbell H, Varley T, et al. Mapping ICD-10 and ICD-10-CM Codes to Phecodes: Workflow Development and Initial Evaluation. JMIR Med Inform. 2019;7(4):e14325.

37. Willer CJ, Li Y, Abecasis GR. METAL: fast and efficient meta-analysis of genomewide association scans. Bioinformatics. 2010;26(17):2190-1.

38. Denny JC, Ritchie MD, Basford MA, Pulley JM, Bastarache L, Brown-Gentry K, et al. PheWAS: demonstrating the feasibility of a phenome-wide scan to discover gene-disease associations. Bioinformatics. 2010;26(9):1205-10.

39. Denny JC, Bastarache L, Ritchie MD, Carroll RJ, Zink R, Mosley JD, et al. Systematic comparison of phenome-wide association study of electronic medical record data and genome-wide association study data. Nat Biotechnol. 2013;31(12):1102-10.

40. Walters RG, Jacquemont S, Valsesia A, de Smith AJ, Martinet D, Andersson J, et al. A new highly penetrant form of obesity due to deletions on chromosome 16p11.2. Nature. 2010;463(7281):671-5.

41. Kendall KM, Rees E, Bracher-Smith M, Legge S, Riglin L, Zammit S, et al. Association of Rare Copy Number Variants With Risk of Depression. JAMA Psychiatry. 2019;76(8):818-25.

42. O'Dushlaine C, Ripke S, Ruderfer DM, Hamilton SP, Fava M, losifescu DV, et al. Rare copy number variation in treatment-resistant major depressive disorder. Biol Psychiatry. 2014;76(7):536-41. 
medRxiv preprint doi: https://doi.org/10.1101/2021.06.09.21258554; this version posted June 12, 2021. The copyright holder for this preprint (which was not certified by peer review) is the author/funder, who has granted medRxiv a license to display the preprint in perpetuity.

It is made available under a CC-BY 4.0 International license .

43. Castro VM, Minnier J, Murphy SN, Kohane I, Churchill SE, Gainer V, et al. Validation of electronic health record phenotyping of bipolar disorder cases and controls. Am J Psychiatry. 2015;172(4):36372.

44. Veasey SC, Rosen IM. Obstructive Sleep Apnea in Adults. New England Journal of Medicine. 2019;380(15):1442-9.

45. Allach El Khattabi L, Heide S, Caberg JH, Andrieux J, Doco Fenzy M, Vincent-Delorme C, et al. 16p13.11 microduplication in 45 new patients: refined clinical significance and genotype-phenotype correlations. J Med Genet. 2020;57(5):301-7.

46. Gillentine MA, Schaaf CP. The human clinical phenotypes of altered CHRNA7 copy number. Biochem Pharmacol. 2015;97(4):352-62.

47. Balu DT, Presti KT, Huang CCY, Muszynski K, Radzishevsky I, Wolosker H, et al. Serine Racemase and D-serine in the Amygdala Are Dynamically Involved in Fear Learning. Biol Psychiatry. 2018;83(3):273-83.

48. Beesley LJ, Salvatore M, Fritsche LG, Pandit A, Rao A, Brummett C, et al. The emerging landscape of health research based on biobanks linked to electronic health records: Existing resources, statistical challenges, and potential opportunities. Stat Med. 2020;39(6):773-800.

49. Martin AR, Kanai M, Kamatani Y, Okada Y, Neale BM, Daly MJ. Clinical use of current polygenic risk scores may exacerbate health disparities. Nat Genet. 2019;51(4):584-91. 